\title{
O ATENDIMENTO PEDAGÓGICO HOSPITALAR
}

\author{
Cássia Regina Dias Pereira ${ }^{\mathrm{i}} \oplus 0000-0003-1572-7002$ \\ Universidade Estadual do Paraná - UNESPAR/Paranavaí \\ Mônica de Souza Oliveirai ${ }^{\text {ii }}$ 0000-0001-9075-0953 \\ Universidade Estadual do Paraná - UNESPAR/Paranavaí
}

RESUMO: $O$ atendimento pedagógico para crianças hospitalizadas em idade escolar vem tomando cada vez mais espaço nas discussões e pesquisas que envolvem a educação. Esse estudo analisa como essa modalidade de atendimento educacional surgiu e se tornou um campo de atuação para o pedagogo. É uma pesquisa bibliográfica de aprofundamento teórico que analisou qualitativamente os dados coletados sobre o tipo de trabalho que pode ser feito no âmbito hospitalar pelo pedagogo, qual o perfil de formação adequado, a legislação que ampara o atendimento pedagógico hospitalar, e por último destacamos o Serviço de Atendimento à Rede de Escolarização Hospitalar - SAREH no estado do Paraná. O atendimento pedagógico hospitalar no Brasil teve início em 1950, no estado do Rio de Janeiro. A procura por meios de acesso e melhoria desse tipo de atendimento educativo, desde as primeiras ações oferecidas foi contínua, conforme atestam os autores consultados. Porem as ações de atendimento só foram intensificadas após a homologação da Constituição Federal em 1988, que instituiu a educação como diretos de todos os cidadãos, ou seja, inclusive daquelas crianças que estejam hospitalizadas. Em 1990 a Conferência Mundial sobre Educação para todos, aprovou a Declaração Mundial sobre Educação para Todos. Em 1994 foi aprovada da Declaração de Salamanca que tratou das com necessidades educativas especiais com acesso e qualidade por intermédio da UNESCO e do Banco Mundial. Em 1990 o Estatuto da Criança e do Adolescente, e 1996 a Lei de Diretrizes e Bases da Educação Nacional $n^{\circ} 9394$ favoreceram a implantação do atendimento pedagógico escolar nos hospitais, porém esse serviço ainda não foi implantado na maioria dos hospitais brasileiros.

PALAVRAS-CHAVE: Pedagogia hospitalar. Programas de atendimento. Escolarização.

\section{THE HOSPITAL PEDAGOGICAL SERVICE}

ABSTRACT: Pedagogical assistance for hospitalized children of school age has been increasingly taking place in discussions and research involving education. This study analyzes how this type of educational assistance emerged and became a field of action for the educator. It is a bibliographic research with a theoretical deepening that qualitatively analyzed the data collected on the type of work that can be done in the hospital by the pedagogue, which is the appropriate training profile, the legislation that supports the pedagogical hospital care, and finally we highlight the Service of Service to the Hospital Schooling Network - SAREH in the state of Paraná. Pedagogical hospital care in Brazil began in 1950, in the state of Rio de Janeiro. The search for means of access and improvement of this type of educational assistance, since the first actions offered was continuous, as attested by the consulted authors. However, the care actions were only intensified after the ratification of the Federal Constitution in 1988, which instituted education as rights of all citizens, that is, including those children who are hospitalized. In 1990 the World Conference on Education for All approved the World Declaration on Education for All. In 1994, the Salamanca Declaration was approved, which addressed those with special educational needs with access and quality through UNESCO and the World Bank. In 1990, the Child and Adolescent Statute, and 1996 the National Education Guidelines and Bases Law No. 9394 favored the implementation of school pedagogical assistance in hospitals, but this service has not yet been implemented in most Brazilian hospitals.

KEYWORDS: Hospital pedagogy. Attendance programs. Schooling. 


\section{1- Introdução}

$\mathrm{O}$ atendimento pedagógico hospitalar também denominado de pedagogia hospitalar é um tema que se reveste de uma importância crucial nos dias atuais a partir da constatação de que sua análise se volta para a maneira como é conduzido o atendimento de crianças e jovens, que necessitam permanecer hospitalizados por longos períodos. A relevância deste estudo devese ao fato de contribuir para a difusão do conhecimento sobre a linha de ação da pedagogia hospitalar, a importância da formação de professores para atuar nesse ambiente, e divulgar os programas existentes no Paraná. A questão que embasa a pesquisa é investigar como educação pode contribuir positivamente para a restauração da saúde de crianças e jovens hospitalizados por longos períodos.

Faz parte de nossas vidas, o fato de ficarmos doentes. Em alguns casos, dependendo da gravidade, a patologia pode requerer longo período de hospitalização. Fato que interfere e afeta de várias maneiras a cotidiano do paciente.

$\mathrm{Na}$ vida da criança, a necessidade de permanência no ambiente hospitalar por grande período de tempo, ocorre de forma mais rude, interferindo no contexto mais importante da vida de uma pessoa, a infância (FONTES, 2004).

O fato de uma criança estar hospitalizada, não faz com que ela deixe de ser criança, e neste cenário, a pedagogia hospitalar/ projetos e programas de atendimento pedagógico hospitalar, adquirem um papel significativo, porque possibilita ao paciente (criança internada), uma possibilidade de se manter realizando atividades lúdicas e escolares, associadas ao tratamento de sua saúde.

$\mathrm{Na}$ condição de internamento hospitalar vivenciado pela criança, muitas vezes sua autoestima fica abalada, nesse sentido a intervenção pedagógica do professor, objetiva resgatar a autoestima afetada, através do ouvir e do falar, pois a criança possui uma necessidade peculiar de falar sobre sua doença, necessitando sempre de alguém que lhe escute (FONTES, 2004).

A educação no contexto hospitalar caracteriza-se por possibilitar a criança o conhecimento e compreensão deste espaço desconhecido; trazendo a ela um novo significado a respeito de sua doença e do espaço em que está inserida, acolhendo de forma ativa a ansiedade e as dúvidas da criança, criando situações de reflexão coletiva, levando a construção de novos conhecimentos que contribuam para a compreensão do sentido da vida, possibilitando uma melhora do quadro clínico da criança.

Desse modo, a pedagogia hospitalar deve valorizar o espaço de expressão (coletiva ou individual) e acolhimento das emoções. Entendo que a compreensão das causas que estão na 
origem da emoção pode contribuir para dissipá-la ou, ao menos, atenuá-la, trazendo bem-estar físico e emocional. Todavia, esse tipo de saber não deve ser exclusivo do domínio infantil.

Como professores, também temos de saber lidar com nossas emoções para conviver com as emoções do outro. Temos de respeitar a tristeza e o silêncio da criança hospitalizada. Daí a concepção e a prática de uma escuta pedagógica e de uma educação da emoção, ampliando o conceito de educação atualmente difundido (FONTES, 2004, p.135).

Juntamente com a criança, o professor deve estudar as informações e conhecimentos relacionados à sua doença e profilaxia, atuando juntamente com os responsáveis da criança, transformando os conhecimentos espontâneos em conhecimentos científicos, fazendo com que o ambiente hospitalar se torne também um ambiente de aprendizagem.

A desmistificação de o ambiente hospitalar fica a caráter do professor, fazendo com que o medo que paralisa e cria resistência na criança desapareça, provocando assim, o surgimento da intimidade com o espaço e com as pessoas que ali atuam, cumprindo dessa forma o direito a educação que é assegurado pela Constituição Federal (CF) de 1988 no seu artigo 205, pois o desenvolvimento da criança tem que ser preservado e incentivado de maneira inclusiva.

$\mathrm{O}$ atendimento pedagógico no ambiente hospitalar proporciona uma melhora no quadro do paciente, pois tendo um professor ao seu lado, que conforme podemos examinar historicamente, é uma figura muito importante para o indivíduo em desenvolvimento, se faz positiva, pois ajuda na redução da ansiedade, a qual surge no momento da internação, fazendose necessário o processo de escuta.

O atendimento pedagógico hospitalar teve início em meados de 1935 na França, lá aconteceu a primeira intervenção de caráter pedagógico no ambiente hospitalar, isso por conta da inauguração de uma escola para crianças inadaptadas por Henri Sellier, e ainda, segundo Loss (2014), logo após a II Grande Guerra Mundial, houve uma ampliação devido às necessidades emergentes na época em alguns países da Europa, que por conta dos combates que aconteciam recebiam os "efeitos colaterais", crianças mutiladas e/ou com as mais diversas doenças que mereciam atenção e atendimento especializado.

É importante ressaltar que, historicamente e conforme as pesquisas, o atendimento hospitalar tem sua primeira manifestação e caracterização como tal em 1893 no Brasil, mas o mesmo era bem escasso, podendo ser considerado como um atendimento pré-hospitalar. Esse atendimento ganhou forma e força a partir de meados da década de 50, porem mesmo assim na atualidade o atendimento não pode ser oferecido em todos os hospitais com casos de internação média ou longa para as crianças/adolescentes, seja por falta de estrutura, financiamento ou escassez de profissionais capacitados. 
Segundo Borges; Borges (2012, p. 188) "no Brasil, o primeiro hospital a trabalhar com a classe hospitalar foi o Hospital Municipal Jesus no Rio de Janeiro no ano de 1950. O referido hospital funciona até hoje com o atendimento educacional”, em relação ao desenvolvimento do país, esse é um entendimento à população muito recente, e desde este início portas foram sendo abertas, provendo esse atendimento, um exemplo disso é a aprovação do Estatuto da Criança e do Adolescente Hospitalizado em 1995.

Em dezembro de 2002, em consonância ao objetivo de proporcionar um aumento e melhora no atendimento hospitalar, o Ministério de Educação e Cultura - MEC elaborou, aprovou e pulicou o documento intitulado "Classe Hospitalar e atendimento pedagógico domiciliar", por meio dele o MEC procurou delinear e estruturar ações para proporcionar uma melhora na organização de um sistema da área de atendimento escolar no ambiente hospitalar, neste documento, o governo procurou através da Secretaria de Educação Especial, trazer estratégias e orientações para esse tipo de atendimento.

O documento destaca o perfil de formação do profissional que irá trabalhar neste âmbito, recomenda-se que tenha conhecimento (mesmo que seja breve noção) sobre as doenças, as condições fisiológicas e psicológicas dos pacientes/alunos e apresentar visão clínica e pedagógica para com a criança.

No documento sobre a Política Nacional de Educação Especial elaborado e colocado em vigor pelo MEC em 1994, encontramos uma definição para o atendimento pedagógico hospitalar que é conceituado como "um ambiente hospitalar que possibilita o atendimento educacional de crianças e jovens internados que necessitam de educação especial e que estejam em tratamento hospitalar" (BRASIL, 1994, p. 20), porém é importante ressaltar que não são todos os ambientes que tem a possibilidade de usufruírem desta prática.

No que diz respeito à formação profissional e/ou continuada para os pedagogos poderem atuar no ambiente hospitalar, há a possibilidade de realizar especialização após o término do curso, fazer outra graduação para complementação de formação ou ainda, existe a possibilidade de haver a disciplina de Fundamentos da Pedagogia Hospitalar como componente curricular do curso. Como já ocorre em alguns cursos de pedagogia que procederam a adequações na matriz curricular em busca de melhoria e especificações necessárias, mas producentes com as necessidades da sociedade (que se caracteriza como o público alvo), com um olhar crítico para uma formação integral do profissional.

Diante disso o atendimento da pedagogia hospitalar se fez e se faz imprescindível diante das necessidades emergentes e ainda por dar continuidade nas atividades escolares com as quais 
a criança ou o jovem estavam ligados antes do surgimento da necessidade do internamento hospitalar.

\section{O papel do pedagogo para além do conhecimento cognitivo}

O pedagogo durante sua formação tem a possibilidade de cursar, dependendo da matriz curricular do curso disciplinas como; Psicologia, Fundamentos da Educação Infantil, Alfabetização e Letramento, e em algumas IES (Instituições de Ensino Superior), a matriz oferece a disciplina na área hospitalar ${ }^{1}$, objeto de estudo dessa pesquisa. Essa possibilidade permite ao estudante ter uma formação mais ampla e com conhecimento para atuar em situações que o ambiente hospitalar implica.

[...] os pedagogos necessitam de formação e preparação para atuarem em espaços que não seja apenas os escolares, superando a visão de que seu único campo de atuação consiste nos espaços escolares, e para isso a Universidade precisa proporcionar oportunidades para que essa formação aconteça criando condições para que o pedagogo conheça essas diferentes possibilidades de atuação (LOSS, 2014, p. 88).

Tendo esse respaldo como base, a função do pedagogo no ambiente hospitalar se torna essencial para o desenvolvimento da criança em seu aspecto cognitivo, bem como para uma melhora em seu equilíbrio psicológico e melhora em seu quadro de humor e, talvez até em seu estado clínico. Considerando que nesses casos a criança/jovem e família ficam fragilizados com a realidade em que se encontram, pois é difícil para ambos a ruptura de uma determinada rotina para o hospital, em intervenção ou internamento. Por este fator, o formando tem que saber como atuar nestes casos. Sendo assim,

A ação pedagógica no contexto hospitalar contribui para que a criança e o adolescente não se sintam tão tristes por não estarem na escola ou em sua casa, possibilita que a aprendizagem escolar tenha continuidade e ajuda nos aspectos emocionais, fazendo-os centrarem forças no "esquecimento" da situação vivenciada de enfermidade, a partir de trabalhos pedagógicos que contagiam com a esperança, a alegria, os sonhos e os projetos (LOSS, 2014, p. 65).

\footnotetext{
1 A Universidade Federal da Fronteira Sul (UFFS) na matriz curricular do curso de Pedagogia apresenta a Disciplina de Fundamentos da Pedagogia Hospitalar. Isso procede conforme o Projeto Pedagógico do Curso de Graduação em Pedagogia - Licenciatura, elaborado e aprovado em 2010.
} 
O pedagogo tendo conhecimentos que possibilitem essa melhora, e utilizando a seu favor os materiais disponíveis nas brinquedotecas dos hospitais, quando elas existem, ou em atividades pedagógicas planejadas para cada criança ou quando possível pequenos grupos delas, procurando manter o caráter lúdico das atividades propostas sem perder o objetivo pedagógico da atividade e com intuito de observar a resposta da criança/jovem, para que aos poucos possa ir se aproximando de cada paciente/aluno, a ponto de procurar soluções para que o ambiente hospitalar não os distancie severamente da realidade que o cercava antes da doença que motivou sua internação.

É interessante também que o pedagogo além de ter especialização para ser licenciado a trabalhar nestes ambientes, tenha formação em enfermagem ou em outra área da saúde, para conhecer também os termos médicos/técnicos relacionados à doença do paciente, possibilitando assim uma maior compreensão da criança como um todo.

Toda hospitalização está relacionada por meio de uma enfermidade ou outra situação que se instalou e levou a internação em contexto hospitalar, o que significa, no organismo do ser humano, uma certa ruptura, cujo efeito resulta em impedimentos geradores de mecanismos de adaptação. Diante disso, o organismo responde, satisfazendo demandas fundamentais como: Compensação dos subsistemas, alterando funções do organismo. - Esforço por adaptar todo o organismo às circunstâncias que se impõem no ambiente em que se encontra (MATOS; MUGIATTI, 2009, p. 100).

Um pedagogo que tenha na sua formação um leque de conhecimentos sobre o ensino e aprendizagem e também sobre a área da saúde, adquire mesmo que superficialmente, atribuições necessárias para um bom atendimento e uma satisfatória intervenção pedagógica. Atividades que trabalham de uma maneira diversificada com a criança contribuem para um melhor desenvolvimento cognitivo, no sentido lato $^{2}$, pois se considera que mesmo internado, a criança/adolescente se encontra imerso em florescimento no âmbito de aprender.

Planejar e desenvolver atividades lúdicas que tenham fundamento e especificidades permeadas pelas exigências do currículo permite que o paciente/alunado, no momento da aprendizagem, interiorize os conhecimentos através do concreto (ato de brincar, atividades diferenciadas), esquecendo, mesmo que momentaneamente, de sua realidade no hospital.

De acordo com o Referencial Curricular Nacional para a educação infantil: Volume I

\footnotetext{
${ }^{2}$ Este aspecto de lato, pelo fato de trabalhar atribuições e conteúdos em larga escala, de modo que a criança não se sinta totalmente deslocada quando retornar à sua realidade escolar, pois a mesma continuará aprendendo e desenvolvendo suas capacidades cognitivas conforme sua idade, porém não será tão severamente cobrada como se estivesse inseria no ambiente regular de ensino.
} 
A brincadeira é uma linguagem infantil que mantém um vínculo essencial com aquilo que é o 'não-brincar'. Se a brincadeira é uma ação que ocorre no plano da imaginação isto implica que aquele que brinca tenha o domínio da linguagem simbólica. Isto quer dizer que é preciso haver consciência da diferença existente entre a brincadeira e a realidade imediata que lhe forneceu conteúdo para realizar-se. Nesse sentido, para brincar é preciso apropriar-se de elementos da realidade imediata de tal forma a atribuir-lhes novos significados. Essa peculiaridade da brincadeira ocorre por meio da articulação entre a imaginação e a imitação da realidade. Toda brincadeira é uma imitação transformada, no plano das emoções e das ideias, de uma realidade anteriormente vivenciada (BRASIL, 1998, p. 27).

No momento das brincadeiras, a criança/adolescente que se transforma em paciente hospitalizado, tem a possibilidade de "viajar" em dimensões que, ora servirão de refúgio para com a doença, ora de fonte para energias e alegrias para continuar em frente, além de permitir que a mesma possa saber diferenciar a realidade da fantasia. Importante destacar que não é foco desta pesquisa apresentar modelos de atividades a serem desenvolvidas pelo pedagogo hospitalar, iremos contextualizar sobre as políticas públicas para esse atendimento, quanto à formação de professores e ao programa estadual SAREH, que simultaneamente intercalam e integram esses aspectos e as atividades realizadas, porém, este não será o nosso foco central, apenas ressaltamos as pesquisas que mostram como esses aspectos tendem a ser positivos.

O pedagogo hospitalar deve saber o modo de e quando seguir em frente com o paciente, como saber a hora de "falar sério", como chamar a atenção sem alarmar a criança/adolescente que se encontra hospitalizada, como lidar com os momentos de "altos e baixos" dos pacientes mirins. Para isso o pedagogo tem que ter domínio sobre as teorias de conhecimento, as especificidades da emoção e a influência da linguagem utilizada e integrar com os procedimentos lúdicos ${ }^{3}$. Diante disso,

Em relação ao escolar doente/hospitalizado, o auxílio pedagógico, propriamente dito, centra-se na sua questão mais específica, levando em consideração as necessidades a que está sujeito, neste momento tão especial do seu desenvolvimento. Sendo assim, a assistência pedagógica, na hospitalização, sugere uma ação educativa que se adapta às manifestações de cada criança/adolescente, em diferentes circunstancias, nos enfoques didáticos, metodológicos, lúdicos e pessoais. Nesse sentido, ela apresenta, em todos os momentos, um alto grau de flexibilidade e adaptabilidade às estruturas (MATOS; MUGIATTI, 2009, p. 101).

\footnotetext{
${ }^{3}$ Quanto a esses aspectos peculiares, de conhecimento, emoção e linguagem atrelados à ludicidade, não adentraremos neste trabalho, mas indicamos para leitura o seguinte trabalho de Oliveira, Dias e Roazzi (2003) intitulado como "O Lúdico e suas Implicações nas Estratégias de Regulação das Emoções em Crianças Hospitalizadas", disponível em: $<$ www.scielo.br/pdf/prc/v16n1/16794.pdf >. OLIVEIRA, Sâmela Soraya Gomes de; DIAS, Maria da Graça B. B.; ROAZZI, Antônio. O Lúdico e suas Implicações nas Estratégias de Regulação das Emoções em Crianças Hospitalizadas. [S/L]: Psicologia: Reflexão e Crítica, 2003, 16. p.1-13.
} 
Diante dessa realidade, o profissional que atenderá e prestará atendimento a esses sujeitos deve estar preparado para lidar com a situação, ter habilidades que o permitam trabalhar de modo multidisciplinar, ou então, até interdisciplinar ou transdisciplinar. Tendo respaldo da realização do atendimento prestado, poderá trabalhar da melhor maneira possível a atender o paciente hospitalizado em idade escolar.

\section{Políticas públicas para a pedagogia hospitalar nacional e no Estado do Paraná}

No Brasil encontramos a primeira lei que tratou do atendimento pedagógico diferenciado para alunos com problemas de saúde em 1969. A lei n 1.044 de 21 de outubro, assim regulamentou o atendimento:

Art. $1^{\circ}$ São considerados merecedores de tratamento excepcional os alunos de qualquer nível de ensino, portadores de afecções congênitas ou adquiridas, infecções, traumatismo ou outras condições mórbitas, determinando distúrbios agudos ou agudizados, caracterizados por:

a) incapacidade física relativa, incompatível com a frequência aos trabalhos escolares; desde que se verifique a conservação das condições intelectuais e emocionais necessárias para o prosseguimento da atividade escolar em novos moldes;

b) ocorrência isolada ou esporádica;

c) duração que não ultrapasse o máximo ainda admissível, em cada caso, para a continuidade do processo pedagógico de aprendizado, atendendo a que tais características se verificam, entre outros, em casos de síndromes hemorrágicos (tais como a hemofilia), asma, cartide, pericardites, afecções osteoarticulares submetidas a correções ortopédicas, nefropatias agudas ou subagudas, afecções reumáticas, etc.

Art. $2^{\circ}$ Atribuir a esses estudantes, como compensação da ausência às aulas, exercício domiciliares com acompanhamento da escola, sempre que compatíveis com o seu estado de saúde e as possibilidades do estabelecimento.

A partir da promulgação da Constituição Brasileira em 1988, a população conquistou espaços que foram instituídos como genuínos e propriamente como sendo direitos de cada cidadão, mas a luta por melhores condições não parou por aí, mesmo que em 1990, a nível internacional, aconteceram determinados eventos que entrariam para a história por procurarem defender e garantir mais direitos de caráter humanitários.

Em 1990 acontece a Conferência Mundial sobre Educação para todos, na qual é aprovada a Declaração Mundial sobre Educação para Todos, em 1994 a aprovação da Declaração de Salamanca com relação às necessidades educativas especiais com acesso e 
qualidade por intermédio da UNESCO e do Banco Mundial, já em nível nacional, em 1990 é aprovado o ECA - Estatuto da Criança e do Adolescente, em 1996 é aprovada a Lei de Diretrizes e Bases da Educação Nacional no 9394.

Diante disso, há também a aprovação de portarias e resoluções que reafirmam os direitos dos cidadãos, em específico das crianças e adolescentes em idade escolar, no caso deste estudo com relação às crianças hospitalizadas, assim em 1995, é aprovada a Resolução no 41 do Conselho Nacional dos Direitos da Criança e do Adolescente, que dispõe sobre os direitos das crianças e adolescentes que se encontrarem em estado de hospitalização, internamento, e/ou intervenção médica, sejam, em seu nascimento ou em qualquer outro estágio de sua vida, os artigos são:

I. Direito à proteção à vida e à saúde, com absoluta prioridade e sem qualquer forma de discriminação.

II. Direito a ser hospitalizado quando for necessário ao seu tratamento, sem distinção de classe social, condição econômica, raça ou crença religiosa.

III. Direito a não ser ou permanecer hospitalizado desnecessariamente por qualquer razão alheia ao melhor tratamento de sua enfermidade.

IV. Direito a ser acompanhado por sua mãe, pai ou responsável, durante todo o período de sua hospitalização, bem como receber visitas.

V. Direito a não ser separado de sua mãe ao nascer.

VI. Direito a receber aleitamento materno sem restrições.

VII. Direito a não sentir dor, quando existam meios para evitá-la.

VIII. Direito a ter conhecimento adequado de sua enfermidade, dos cuidados terapêuticos e diagnósticos a serem utilizados, do prognóstico, respeitando sua fase cognitiva, além de receber amparo psicológico, quando se fizer necessário.

IX. Direito a desfrutar de alguma forma de recreação, programas de educação para a saúde, acompanhamento do "curriculum" escolar, durante sua permanência hospitalar.

X. Direito a que seus pais ou responsáveis participem ativamente do seu diagnóstico, tratamento e prognóstico, recebendo informações sobre os procedimentos a que será submetido.

XI. Direito a receber apoio espiritual e religioso conforme prática de sua família.

XII. Direito a não ser objeto de ensaio clínico, provas diagnósticas e terapêuticas, sem o consentimento informado de seus pais ou responsáveis e o seu próprio, quando tiver discernimento para tal.

XIII. Direito a receber todos os recursos terapêuticos disponíveis para a sua cura, reabilitação e/ou prevenção secundária e terciária.

XIV. Direito à proteção contra qualquer forma de discriminação, negligência ou maus tratos.

XV. Direito ao respeito à sua integridade física, psíquica e moral.

XVI. Direito à preservação de sua imagem, identidade, autonomia de valores, dos espaços e objetos pessoais.

XVII. Direito a não ser utilizado pelos meios de comunicação, sem a expressa vontade de seus pais ou responsáveis, ou a sua própria vontade, resguardando-se a ética. 
XVIII. Direito à confidência dos seus dados clínicos, bem como Direito a tomar conhecimento dos mesmos, arquivados na Instituição, pelo prazo estipulado em lei.

XIX. Direito a ter seus direitos Constitucionais e os contidos no Estatuto da Criança e do Adolescente, respeitados pelos hospitais integralmente.

$\mathrm{XX}$. Direito a ter uma morte digna, junto a seus familiares, quando esgotados todos os recursos terapêuticos disponíveis (BRASIL, 1995, p. 04-05).

Desta forma, conforme o artigo IX desta resolução fica ressalvado o atendimento pedagógico escolar das crianças e adolescentes dentro do ambiente hospitalar e diante disso, mesmo que implicitamente, o atendimento de caráter social, moral, e humanizado fica sendo um direito garantido por Lei para crianças e adolescentes hospitalizados, e desta maneira sendo possível o atendimento educacional no ambiente hospitalar, desde que este atendimento esteja de acordo com a legislação vigente, podendo ser realizado tanto no hospital como em domicílio, mais posteriormente em 2001 é aprovada a Resolução no 02/2001 - CNE/CEB, que institui as Diretrizes Nacionais para Educação Especial Básica, na qual em, seu art. 13 é colocado de modo claro e objetivo as especificidades do atendimento escolar/hospitalar,

Art. 13. Os sistemas de ensino, mediante ação integrada com os sistemas de ensino, mediante ação integrada com os sistemas de saúde, devem organizar o atendimento educacional especializado a alunos impossibilitados de frequentar as aulas em razão de tratamento de saúde que implique internação hospitalar, atendimento ambulatorial ou permanência prolongada em domicílio (BRASIL, 2001, p. 4).

O resguardo do direito das crianças e adolescentes em idade escolar se concretiza quando há a ação conjunta dos órgãos da área da saúde com a educacional através de parcerias que possibilitarão a integração das escolas nos hospitais, por meio das classes hospitalares ou atendimento pedagógico hospitalar, ou por meio do atendimento pedagógico domiciliar, ambos com o mesmo objetivo,

[...] dar continuidade ao processo de desenvolvimento e ao processo de aprendizagem de alunos matriculados em escola de educação básica, contribuindo para seu retorno e reintegração ao grupo escolar, e desenvolver currículo flexibilizado com crianças, jovens e adultos não matriculados no sistema educacional local, facilitando seu posterior acesso à escola regular (BRASIL, 2001, p. 4).

A importância da continuidade das atividades escolares serve de apoio para que o paciente se sinta ainda em sua realidade, não sofrendo bruscamente com a ruptura de seu 
cotidiano por conta de uma doença repentina ou de um possível tratamento extenso, a harmonia entre a realidade hospitalar e a escolar deve estar presente, para que quando acontecer sua volta à escola a mesma seja tranquila.

Ficam claros e evidentes os encaminhamentos das políticas para um melhor atendimento dos cidadãos em caso de necessidades de encaminhamento médico, com a maior possibilidade de um atendimento cada vez mais humanitário, isso em nível nacional.

O Estado do Paraná, diante da necessidade do mesmo e considerando a legislação vigente, é que em maio de 2007 delibera a Resolução no 2527 (25 de maio de 2007) e então institui Serviço de Atendimento à Rede de Escolarização Hospitalar - SAREH, segundo o portal Dia a Dia Educação do Governo Federal, o SAREH nada mais se caracterizaria como sendo um serviço que

[...] objetiva o atendimento educacional aos estudantes que se encontram impossibilitados de frequentar a escola, em virtude de situação de internamento hospitalar ou tratamento de saúde, permitindo-lhes a continuidade do processo de escolarização, a inserção ou a reinserção em seu ambiente escolar (SEED/PR, 2018, p. 01).

Segundo Cirino e Menezes (2017, p. 05) “o Serviço de Atendimento à Rede de Escolarização Hospitalar - SAREH, [...] busca estabelecer o direito ao atendimento escolar hospitalar e está amparado legalmente.”, conforme ressaltamos, mesmo que escassamente no estado do Paraná com um total de 399 cidades e municípios, o programa conta com 19 instituições (Dados Portal Dia a Dia, 2018), estas instituições, segundo a resolução em seu artigo 2, são aquelas que são conveniadas e habilitadas pelo fato de que mantiveram o Termo de Cooperação Técnica com a SEED “Art. 2. ${ }^{\circ}$ O Serviço de Atendimento à Rede de Escolarização Hospitalar será ofertado nas instituições que mantiverem Termo de Cooperação Técnica com a Secretaria de Estado da Educação.” (PARANÁ, 2007, p. 01).

O atendimento pedagógico realizado pelo SAREH é e estruturado em cada instituição de saúde com equipes formadas por uma pedagoga, que cumpre a carga horária de 40 horas/aulas semanais e três professores, organizados por área do conhecimento, [...] Ciências Exatas, Códigos e Linguagens e Ciências Humanas, com carga horária de 20 horas/aulas semanais. O atendimento pedagógico é organizado em 4 (quatro) ou 5 (cinco) dias da semana no período vespertino, de segunda-feira à sexta-feira, de acordo com a demanda e necessidade apresentada por cada instituição de saúde. [...] O atendimento pedagógico é organizado de acordo com a etapa e ano que o estudante está matriculado na Educação Básica, conforme princípios da legislação da Educação Nacional e as Diretrizes Curriculares Estaduais Orientadoras da 
Educação Básica do Estado do Paraná (CIRINO \& MENEZES, 2017, p. 0506).

A Instrução no 006 / 2008 - SUED/SEED- PR estabeleceu os procedimentos para a implantação e funcionamento do Serviço de Atendimento à Rede de Escolarização Hospitalar. Nela são definidos claramente de que maneira será desenvolvido o trabalho dos profissionais da SEED e a contra partida das instituições hospitalares, nas quais o programa SAREH foi implantado.

Devido ao fato de que o programa SAREH tem uma proposta de ação bem delineada e atua de forma colaborativa com os hospitais conveniados, optamos por transcrever parcialmente parte da instrução $n^{\circ}$ 006/2008, com o objetivo de melhor identificar o trabalho do pedagogo dentro do programa e possibilitar maior conhecimento sobre sua proposta de atuação.

A instrução n ${ }^{\circ}$ 006/2008 estrutura o SAREH no Estado do Paraná nos seguintes termos:

1. O Serviço de Atendimento à Rede de Escolarização Hospitalar visa o atendimento educacional público, aos educandos matriculados ou não na Educação Básica, nos seus níveis e modalidades, impossibilitados de frequentar a escola por motivos de enfermidade, em virtude de situação de internamento hospitalar ou de outras formas de tratamento de saúde, oportunizando a continuidade no processo de escolarização, a inserção ou a reinserção em seu ambiente escolar.

2. O Serviço de Atendimento à Rede de Escolarização Hospitalar será ofertado nas instituições que mantiverem Termo de Cooperação Técnica com a Secretaria de Estado da Educação.

3. O Serviço de Atendimento à Rede de Escolarização Hospitalar será desenvolvido por professores e pedagogos do Quadro Próprio do Magistério, previamente selecionados, conforme Edital publicado pela Secretaria de Estado da Educação. [...]

7. São atribuições do Pedagogo:

a) coordenar, acompanhar e avaliar o trabalho pedagógico, bem como organizar os materiais e equipamentos do Serviço de Atendimento à Rede de Escolarização Hospitalar;

b) observar a recomendação médica para liberação dos educandos para que recebam Atendimento Pedagógico;

c) promover encontros a fim de oportunizar a troca de experiências entre os docentes;

d) elaborar, em conjunto com os professores e profissionais da instituição conveniada, o Plano de Ação Pedagógico-Hospitalar; 
e) articular ações com os profissionais da instituição conveniada, para o desenvolvimento do Serviço de Atendimento à Rede de Escolarização Hospitalar;

f) manter contato com a família, com o responsável pelo Serviço de Atendimento à Rede de Escolarização Hospitalar do Núcleo Regional de Educação e com a escola de origem do educando.

Diante do conhecimento sobre as políticas públicas elaboradas e aplicadas com a finalidade de proporcionar o atendimento hospitalar para os pacientes em idade escolar, fica evidente a necessidade da formação e capacitação de profissionais aptos para atuarem nesta área de trabalho.

\section{O SAREH e suas possibilidades para a atuação de professores nos hospitais: novos caminhos para o trabalho pedagógico}

O programa SAREH foi instituído no Estado do Paraná em 2007 através da Resolução $\mathrm{n}^{\circ} 2527$ pela Secretaria de Educação do Estado do Paraná (SEED). Com o objetivo de oferecer atendimento pedagógico para os estudantes que se encontram em momento de internação, afastamento do ambiente escolar, ou com a saúde debilitada à um ponto de serem privados da escola, vem possibilitando aos estudantes uma continuidade de seu aprendizado, mas para que esse atendimento ocorra, há a necessidade de que haja profissionais capacitados e formados para prestar esse tipo de atendimento.

O campo de atuação do pedagogo é amplo e com inúmeras possibilidades, sendo que uma dessas é sua atuação no ambiente hospitalar. Esses profissionais podem atuar no âmbito do atendimento pedagógico hospitalar em classes hospitalares ou ainda no atendimento pedagógico domiciliar. Como já exposto anteriormente, o atendimento pedagógico hospitalar se caracteriza por ser um atendimento prestado aos pacientes em idade escolar, que no Estado do Paraná há o programa SAREH - é importante pautar que este só atende aos estudantes de nível estadual e por esse motivo há um envolvimento maior por parte do estado - que por sua vez poderia possibilitar uma correlação entre os poderes municipais e estaduais para melhor atender os estudantes em estado de fragilidade da saúde. Quanto à possibilidade de trabalho, segundo o projeto apresentado pelo Estado do Paraná sobre a apresentação e normalização do SAREH (2007), a classe hospitalar pode ser caracteriza como sendo no geral 
a instalação das classes hospitalares, este atendimento pedagógicoeducacional, tende a ocorrer nas enfermarias, o que denota não haver, por parte dos hospitais, o cuidado com o espaço a ser utilizado por esta modalidade de atendimento. Devemos, então, considerar a necessidade de clarificar aos hospitais a importância do trabalho realizado pelas classes hospitalares, a fim de que estas possam dispor de acomodações mais adequadas para o exercício de suas atividades (PARANÁ, 2007, p. 07).

Fica claro que mesmo tendo ciência da necessidade e regulamentação deste tipo de atendimento, ainda assim encontram-se barreiras que por sua vez dificultam o atendimento que "visa dar continuidade ao processo de desenvolvimento e ao processo de aprendizagem dos educandos hospitalizados.” (PARANÁ, 2007, p. 07), este ainda precisa ser estudado e discutido para que o atendimento em si seja mais efetivo, procurando sugestões e propostas que atendam às necessidades e que tenham possibilidades de serem implementadas.

Há também a possibilidade de o profissional, no caso do nosso enfoque o pedagogo, trabalhar na brinquedoteca hospitalar, que de acordo com Angeliane Dias ${ }^{4}$ (2018) tem o objetivo de proporcionar um certo alivio no sofrimento que a criança/indivíduo hospitalizado passa e também oferece a possibilidade de a mesma entrar em contato com outras crianças viabilizando um contato, talvez o nascimento de uma amizade e até, proporcionando momentos de brincadeiras, e ainda de desenvolver os a linguagem oral e corpora,, ampliar o convívio social e continuar o desenvolvimento global e psicomotor.

Esta possibilidade é fruto da lei $\mathrm{n}^{\circ} 11.104$ de 2005 (BRASIL) que tronou obrigatória a instalação de Brinquedotecas nos hospitais brasileiros, porém não são todos os hospitais que tem condições de oferecer esta instalação. Diante disto, a Brinquedoteca no âmbito hospitalar pode ser caracterizada como um local que "ensina a enfrentar a doença, promovendo a saúde, especialmente se a saúde for concebida como afirmação da vida. [...] Então, propiciar o brincar equivale a reforçar seu prazer de viver". (RODRIGUES, 2013, p. 65).

Neste ambiente, de acordo com o Portal Educação da SEED/PR, a função do pedagogo (a) é o de proporcionar momentos de ludicidade ao paciente infanto-juvenil proporcionar leituras de contos que os permitam "viajar" sem sair do lugar, que seja um local que não haja estresse, seja um local tranquilo e de possibilidade de expressão dos medos, angustias e sonhos reprimidos através de desenhos, pinturas. Tanto para o paciente hospitalizado quanto para os

\footnotetext{
4 Psicóloga recém-formada pelo UNISAL (Centro Universitário Salesiano de São Paulo - Unidade Lorena), e colunista do Portal Educação, além também de ser Brinquedista com 2 anos de experiência e Aluna do curso de pós-graduação em Clínica Cognitivo Comportamental no UNISAL.
} 
familiares que realiza o acompanhamento, o fato é, isso se torna estressante e desgastante, tanto física e psicologicamente.

Segundo a Resolução do Conselho Nacional de Educação, CNE/CEB número 2/01, que institui as Diretrizes Nacionais para Educação Especial a Educação Básica, o atendimento pedagógico domiciliar pode ser encarado como sendo um atendimento que deve:

[...] dar continuidade ao processo de desenvolvimento e ao processo de aprendizagem de alunos matriculados em escolas da Educação Básica, contribuindo para seu retorno e reintegração ao grupo escolar, e desenvolver currículo flexibilizado com crianças, jovens e adultos não matriculados no sistema educacional local, facilitando seu posterior acesso à escola regular (BRASIL, 2001, p. 4).

Considerando tantas especificidades e também que dentro do ambiente hospitalar a reação ao acontecimento e situação atual do indivíduo é diferente, fica claro que para trabalhar neste ambiente, considerado até hostil, o profissional da área da pedagogia precisa ter consciência e preparação de que lá dentro a educação destes indivíduos será diferente daquela realizada em classe escolar, ele tem que ter preparação para lidar com diversas vivências, diversos laudos, diversas situações e necessita identificar as necessidades de cada indivíduo e adaptar os currículos de modo a proporcionar uma melhor aprendizagem ao mesmo. Estes profissionais precisam e necessitam de uma formação e qualificação específica e adequada para que seja capaz e possível de trabalhar com integridade nessa área.

[...] a pedagogia hospitalar deve valorizar o espaço de expressão (coletiva ou individual) e acolhimento das emoções. Entendo que a compreensão das causas que estão na origem da emoção pode contribuir para dissipá-la ou, ao menos, atenuá-la, trazendo bem-estar físico e emocional. Todavia, esse tipo de saber não deve ser exclusivo do domínio infantil. Como professores, também temos de saber lidar com nossas emoções para lidar com as emoções do outro. Temos de respeitar a tristeza e o silêncio da criança hospitalizada. Daí a concepção e a prática de uma escuta pedagógica e de uma educação da emoção, ampliando o conceito de educação atualmente difundido (FONTES, 2004, p. 135).

O estudante de pedagogia, quando em formação, tem a possibilidade de realizar estágio em várias instâncias da educação, no caso desta instituição de ensino superior, a UNESPAR Universidade Estadual do Paraná, o Projeto Político Pedagógico (PPP) e a Matriz Curricular do curso oferecem conhecimentos que lhe possibilitam e capacitam trabalhar na educação infantil, nas series iniciais do ensino fundamental, no ensino fundamental e com complementação pode até atender alunos de Salas de Recursos Multifuncional e sala de apoio, pois temos o privilégio 
de compreender os conteúdos e fundamentos da educação especial e inclusiva, de certo modo somos "preparados" para atuarem com alunos com necessidades educacionais especiais, que não necessariamente diz respeito a indivíduos com algum tipo de deficiência, pois o atendimento de alunos com necessidades educacionais especiais diz respeito ao considerar as especificidades de cada indivíduo fazendo assim que aja um atendimento educacional especializado para agirem nestes casos, uma vez que,

$\mathrm{O}$ atendimento educacional especializado tem como função identificar, elaborar e organizar recursos pedagógicos e de acessibilidade que eliminem as barreiras para a plena participação dos alunos, considerando suas necessidades específicas. As atividades desenvolvidas no atendimento educacional especializado diferenciam-se daquelas realizadas na sala de aula comum, não sendo substitutivas à escolarização. Esse atendimento complementa e/ou suplementa a formação dos alunos com vistas à autonomia e independência na escola e fora dela" (BRASIL, 2008, p. 10).

Diante do exposto, fica evidente que o profissional da Pedagogia pode atuar em diversas áreas da educação, tanto na formal quanto na informal, ampliando consideravelmente as possibilidades do campo profissional e empregatício. Com pós-graduações especificas e complementações/especializações o mesmo pode exercer sua profissão em ONGs, em empresas, em escolas, ou ainda em hospitais; que é o nosso enfoque.

\section{Considerações finais}

Conforme o estudo desenvolvido por essa pesquisa, pudemos notar que o atendimento pedagógico em ambiente hospitalar é relativamente recente como sendo uma prática profissional reconhecida perante a sociedade e perante a lei.

As práticas para formação e qualificação de profissionais para atuarem nesse âmbito são mais recente ainda, sendo possível ocorrer em locais distintos, neste caso em hospitais, porém, nem todos os hospitais contam com profissionais para atuarem nesse âmbito educativo escolar. Há a necessidade de uma reflexão e pesquisas para ampliar a compreensão e a possibilidades de atuação nesta área de atendimento educacional que tende a crescer e a se desenvolver cada vez mais, desta forma, haverá de se preocupar a precisão de uma oferta de aperfeiçoamento e de formação aos profissionais que possam conhecer a atuar no âmbito da pedagogia hospitalar.

No Estado do Paraná com extensão de 399 municípios há somente 19 instituições regulamentadas com o SAREH, que oferta este tipo de serviço de atendimento pedagógico com 
os jovens e adolescentes hospitalizados, não havendo ainda uma regulamentação para o atendimento especializado e direcionado às crianças que se encontram na mesma situação.

A necessidade de políticas na área se torna real diante da existência da problemática, o atendimento pedagógico e escolar à criança em estado de fragilidade por motivos de saúde, isso faz com que a mesma não perca a linha de seu desenvolvimento e não saia totalmente de sua rotina, de sua vida antes da fatalidade de ficar doente, que pode vir a acontecer com qualquer organismo saudável.

Fica claro também que a formação dos profissionais que atuarão na área deve ser considerado e melhorado, pois além de estarem em contato com os estudantes que necessitam dar continuidade em seu aprendizado, sua especificidade deve ser foco de reflexões, assim também como a formação do responsável pelo atendimento pedagógico.

\section{REFERÊNCIAS:}

BRASIL. Constituição da República Federativa do Brasil. 1988. Disponível em: <http://www.planalto.gov.br/ccivil_03/constituicao/constituicao.htm>. Acesso em: 21 fev. 2018.

BRASIL. Estatuto da Criança e Adolescente-ECA. Lei n. 8069, de 13 de julho de 1990. Dispõe sobre o Estatuto da Criança e do Adolescente e dá outras providências. Disponível em:<http://www.crianca.mppr.mp.br/arquivos/File/publi/camara/estatuto_crianca_adolescente _9ed.pdf >. Acesso em: 28 abr. 2018.

BRASIL. Lei $\mathbf{n}^{\mathbf{0}} \mathbf{1 1 . 1 0 4}$, de 21 de março de 2005. Dispõe sobre a obrigatoriedade de instalação de brinquedotecas nas unidades de saúde que ofereçam atendimento pediátrico em regime de internação. Disponível em:< http://www2.camara.leg.br/legin/fed/lei/2005/lei-11104-21marco-2005-536146-norma-pl.html>. Acesso em: 19 maio 2018.

BRASIL. Ministério da Educação. Secretaria de Educação Especial. Política Nacional de Educação Especial na perspectiva da educação inclusiva. Brasília: MEC/SEESP, 2008. Disponível em: arquivos.info.ufrn.br/arquivos/.../nee_do_que_estamos_falando_debora_nunes.pdf >. Acesso em: 24 maio 2018.

BRASIL. Referencial Curricular Nacional para a educação infantil: Volume I - Introdução. Ministério da Educação e do Desporto. Secretaria de Educação Fundamental. Brasília: MEC/ SEF, 1998.

BRASIL. Ministério da Educação. Classe hospitalar e atendimento pedagógico domiciliar: estratégias e orientações. / Secretaria de Educação Especial. - Brasília: MEC/SEESP, 2002. 41p. Disponível em:〈http://portal.mec.gov.br/seesp/arquivos/pdf/livro9.pdf>

BRASIL. Ministério da Educação. Secretaria de Educação Especial. Política Nacional de Educação Especial. Brasília-DF: MEC/SEESP, 1994. Disponível em:< portal.mec.gov.br/arquivos/pdf/politicaeducespecial.pdf>.

BRASIL. Resolução CNE/CEB n. ${ }^{\circ}$ 2, de 11 de setembro de 2001. Diretrizes Nacionais para a Educação Especial na Educação Básica. Disponível em:< portal.mec.gov.br/cne/arquivos/pdf/CEB0201.pdf >. Acesso em: 29 mar. 2018. 
BRASIL. Resolução $n^{\circ} 41$ de outubro de 1995. Conselho Nacional dos Direitos da Criança e do Adolescente. Disponível em: <www.camara.gov.br/sileg/integras/135908.pdf>. Acesso em: 18 maio 2018.

BRASIL. Lei de Diretrizes e Bases da Educação Nacional. Lei n. ${ }^{\circ} 9394$ de 20 de dezembro de 1996. Disponível em: <http://portal.mec.gov.br/seesp/arquivos/pdf/lei9394_ldbn1.pdf〉. Acesso em: 20 maio 2018.

BORGES, Priscila da Rosa; BORGES, Gustavo da Rosa. Contribuição da Pedagogia no Tratamento da Criança Hospitalizada. Caderno pedagógico, Lajeado, v. 9, n. 2, p. 185-196, 2012.

CIRINO, Leila Cristina Mattei; MENEZES, Cinthya Vernizi Adachi de. SAREH: do direito à intervenção pedagógica. In: EDUCARE - Congresso Nacional de Educação, XIII, 2017. Curitiba, PR. ANAIS... p.24.340-24.352.

DECLARAÇÃO de Salamanca Sobre Princípios, Políticas e Práticas na Área das Necessidades Educativas Especiais. Espanha, 1994. Disponível em:< http://portal.mec.gov.br/seesp/arquivos/pdf/salamanca.pdf>. Acesso em: 15 maio 2018.

DIAS, Angeliane Patrícia dos Santos. Brinquedoteca Hospitalar. 2018. 3f. Portal da Educação e Tecnologia Educacional Ltda. Disponível em: <https://www.portaleducacao.com.br/conteudo/artigos/idiomas/brinquedoteca-hospitalar/ 13894>. Acesso em: 17 jun. 2018.

FONTES, Rejane de Souza. A escuta pedagógica à criança hospitalizada: discutindo o papel da educação no hospital. Rio de Janeiro, maio/agosto, $n^{0}$ 29. Revista Brasileira de Educação, 2004.

LOSS, Adriana Salete. Para onde vai a pedagogia? Os desafios da atuação profissional na pedagogia hospitalar. Curitiba: Appris, 2014.

MATOS, Elizete Lúcia Moreira; MUGIATTI, Margarida Maria Teixeira de Freitas. Pedagogia Hospitalar: a humanização integrando educação e saúde. 7. a ed. Petrópolis, RJ: Vozes, 2009.

PARANÁ, Secretaria do Estado do. Resolução n 2527 de 2007. Secretaria de Estado da Educação: SAREH - Serviço de Atendimento a Rede de Escolarização Hospitalar. SEED: Curitiba, 2007.

RODRIGUES, Aparecido Wilson Brinquedoteca Hospitalar: Organização e Administração. Revista InterAtividade, Andradina, SP, v. 1, n. 1, $1^{\circ}$ sem. 2013. P.65-70.

\section{SEED/PARANÁ. Serviço de Atendimento à Rede de Escolarização Hospitalar - SAREH.}

Portal dia a dia Educação. 2018. Disponível em:< http://www.educacao.pr.gov.br/modules/conteudo/conteudo.php?conteudo=63>. Acesso em: 12 abr. 2018.

Instrução n. 006 de 2008. Estabelece os procedimentos para a implantação e funcionamento do Serviço de Atendimento à Rede de Escolarização Hospitalar. Disponível em: $<$ http://www.educacao.pr.gov.br/arquivos/File/instrucoes/instrucao062008.pdf >. Acesso em: 19 jun. 2018.

UNESCO. Declaração Mundial de Educação Para Todos. Conferência de Jomtien, Tailândia. $\quad$ UNICEF. $1990 . \quad$ Disponível $\quad$ em:< https://www.unicef.org/brazil/pt/resources_10230.htm>. Acesso em: 02 jun. 2018. 
' Pedagoga, doutora em Educação pela Universidade Estadual de Maringá (UEM), coordenadora do curso de Pedagogia (UniFatecie) e professora Adjunta da Universidade Estadual do Paraná (UNESPAR/Paranavaí). Email: cassiadiaspereira@yahoo.com.br

ii Acadêmica do curso de graduação em Pedagogia (UNESPAR/Paranavaí). Email: monicasouza_oliveira@hotamil.com 